\title{
Knockdown of KLK12 inhibits viability and induces apoptosis in human colorectal cancer HT-29 cell line
}

\author{
QIANYUAN LI ${ }^{1}$, XIUKOU ZHOU ${ }^{1}$, ZHENGYU FANG $^{1}$ and HUAMIAO ZHOU ${ }^{2}$ \\ Departments of ${ }^{1}$ Anorectal Surgery and ${ }^{2}$ Oncology, The First Affiliated Hospital of Zhejiang Chinese Medical University, \\ Hangzhou, Zhejiang 310006, P.R. China
}

Received January 22, 2019; Accepted July 26, 2019

DOI: $10.3892 /$ ijmm.2019.4327

\begin{abstract}
Kallikrein-related peptidase 12 (KLK12) is overexpressed in cancer tissues including gastric, breast and prostate cancer. However, the role of KLK12 in colorectal cancer is not fully understood. In the present study, the level of KLK12 was determined by performing reverse transcription-polymerase chain reaction (RT-qPCR) in colorectal cancer tissues and cell lines. Lipofectamine ${ }^{\circledR} 2000$ was used to transfect HT-29 cells to overexpress and knockdown KLK12. Cell viability, migration, invasion and apoptosis were detected by MTT, wound healing, Transwell and flow cytometry assays, respectively. The mRNA and protein expression levels of EMT-associated proteins, apoptosis-associated proteins, phosphorylated adenosine monophosphate-activated protein kinase (p-AMPK) and phosphorylated mammalian target of rapamycin (p-mTOR) were determined by RT-qPCR and western blot analysis. It was identified that the KLK12 mRNA levels were increased significantly in colorectal cancer tissues and cell lines. KLK12 small interfering RNA inhibited cell viability, migration and invasion. Furthermore, epithelial-mesenchymal transition (EMT)-associated proteins were altered by siKLK12. Cell apoptosis was induced by KLK12 downregulation, which was demonstrated by the changes in apoptosis-associated proteins; however, KLK12 overexpression produced the
\end{abstract}

Correspondence to: Dr Huamiao Zhou, Department of Oncology, The First Affiliated Hospital of Zhejiang Chinese Medical University, 54 Youdian Road, Shangcheng, Hangzhou, Zhejiang 310006, P.R. China

E-mail: huamiaoz_zhouhm@163.com

Abbreviations: KLK12, kallikrein-related peptidase 12; RT-qPCR, reverse transcription quantitative polymerase chain reaction; p-AMPK, phosphorylated adenosine monophosphate-activated protein kinase; p-mTOR, phosphorylated mammalian target of rapamycin; EMT, epithelial-mesenchymal transition; AMPK, adenosine monophosphate-activated protein kinases; mTOR, mammalian target of rapamycin; KLK, kallikrein; PI, propidium iodide

Key words: kallikrein-related peptidase 12, colorectal cancer, viability, apoptosis opposite effect. SiKLK12 enhanced the expression of p-AMPK and suppressed the expression of p-mTOR, while KLK12 overexpression had the opposite effect. Promotion of KLK12 overexpression-induced cell viability was reversed by 5-aminoimidazole-4-carboxamide ribonucleotide, an activator of the AMPK signaling pathway, and rapamycin, a specific inhibitor of the mTOR signaling pathway. Taken together, the results of the present study indicated that KLK12 was overexpressed in colorectal cancer and may regulate cell behavior, potentially via the AMPK and mTOR pathways.

\section{Introduction}

Colorectal cancer, which is one of the most common types of malignant tumor, has the third highest incidence in men and the second highest incidence in women globally; as a result, colorectal cancer is responsible for a high number of mortalities (1). Radical surgical resection is currently the only method for treating colorectal cancer (2). The primary cause of failure in colorectal cancer surgery is metastasis and tumor recurrence. To date, no effective medication has been identified to inhibit the progression of colorectal cancer. Therefore, the development of protective therapies to suppress the progression of colorectal cancer is necessary in treatment of colorectal cancer.

Epithelial mesenchymal transition (EMT) is a key mechanism in tumor metastasis $(3,4)$. In tumor cells, it is a biological process in which tumor cells allow epithelial cells to transform into cells with mesenchymal phenotype characteristics. During the process, tumor epithelial cells lose their polarity and adhesion among cells is decreased. Through this, interstitial cell characteristics including high migration and invasion ability, anti-apoptosis and degradation of extracellular matrix are obtained $(5,6)$. Therefore, EMT, which serves an important role in the process of tumor metastasis is also a critical condition for invasion and metastasis in colorectal cancer, (7).

As a class of serine/threonine protein kinases in eukaryotic cells, the primary function of adenosine monophosphate-activated protein kinases (AMPK) is to serve as a cellular energy sensor to modulate cellular responses to a low nutrient environment (8). A previous study has indicated that AMPK may regulate cell proliferation, growth and autophagy (9). The tumor suppressor gene serine/threonine kinase 11 may activate AMPK, while tumor suppressor gene TSC complex subunit 2 
(TSC2) is a downstream effector of AMPK (10). These studies provide evidence that AMPK may be a potential target for cancer therapy. Mammalian target of rapamycin (mTOR) is also a serine/threonine protein kinase that regulates cell growth by integrating nutrient and growth factor signaling (11). Numerous studies have indicated that rapamycin may inhibit the proliferation of colorectal cancer cells in vivo and in vitro, and it has been suggested that the mTOR pathway is activated in patients with colorectal cancer $(12,13)$. Therefore, targeting AMPK and mTOR signal pathways may be a promising protective strategy for management of colorectal cancer.

As a class of serine proteases, human kallikrein-related peptidases (KLKs) are encoded by 15 different genes that localize to human chromosome 19q13.4 and have a highly conserved set of gene structures and protein sequences (14). KLKs have been demonstrated to serve important roles in tumor growth and metastasis and are considered as markers for various types of cancer (15). A previous study indicated that KLKs were closely associated with colorectal cancer, as it participated in tumor cell proliferation, apoptosis and prognosis (16). An additional study also identified that KLK promoted the invasion and metastasis of cancer cells by hydrolyzing certain macromolecular substances including the extracellular matrix (ECM), cell adhesion molecules (CAM), and importantly, KLK may degrade almost all ECM molecules (17). It was also demonstrated that the AMPK/TSC2/mTOR signaling pathway was involved in the process of tissue kallikrein to protecting the SH-SY5Y neuronal cell line against oxygen and glucose deprivation-induced injury (18). KLK12 is known as kallikrein 5, and a previous study has demonstrated that KLK12 mRNA levels were upregulated in cancer tissues including gastric, breast and prostate cancer (19). It has been suggested that KLK12 may become a novel tumor biomarker, as data from a recent study demonstrated that the mRNA expression of KLK12 was upregulated in phase III colorectal cancer tissues (20), which also suggested that KLK12 may be involved in the pathogenesis of cancer and malignant changes in tissues (19). However, the mechanisms underlying the effect of KLK12 in human colorectal cancer remain unclear.

The present study was performed to investigate the role of KLK12 in cellular and animal colorectal cancer models, and to identify the potential underlying mechanisms. The results from the study increased understanding on the role of KLK12 in colorectal cancer.

\section{Materials and methods}

Human tissue samples. From May 2016 to May 2017, 45 patients who received radical colorectal cancer resection in The First Affiliated Hospital of Zhejiang Chinese Medical University (Hangzhou, China), were recruited to the study. Specimens were obtained immediately following surgical resection and stored at $-80^{\circ} \mathrm{C}$ for subsequent analysis. All patients had a negative preoperative history of chemotherapy or radiotherapy and no other types of cancer were diagnosed concomitantly. The present study was approved by the Ethical Committee of The First Affiliated Hospital of Zhejiang Chinese Medical University and written informed consent was obtained from each patient.
Immunohistochemistry (IHC). Tissues were fixed with $4 \%$ paraformaldehyde for $24 \mathrm{~h}$ at room temperature and embedded in paraffin. The paraffin-embedded block tissues were cut into $4 \mu \mathrm{m}$ sections. The samples were dehydrated in a graded ethanol (100,-95, 90, 80, 70 and 0\%), and for antigen retrieval, deparaffinized sections were incubated in a microwave oven at $95^{\circ} \mathrm{C}$ for $5 \mathrm{~min}$ and cooled for $1 \mathrm{~h}$ at room temperature. Following washing with PBS for two times, the sections were treated with methanol containing $3 \%$ hydrogen peroxide for $10 \mathrm{~min}$ at room temperature and blocked with $5 \%$ goat serum (Beijing Solarbio Science \& Technology Co., Ltd.) at room temperature for $20 \mathrm{~min}$. Subsequently, anti-KLK12 antibody (cat. no. AF3095; R\&D systems, Inc.) was added to the sections at $4^{\circ} \mathrm{C}$ and incubated for $24 \mathrm{~h}$. Following washing with PBS three times, biotin-labeled goat anti-rabbit IgG secondary antibody (1:5,000, cat. no. ab97049, Abcam) was added to the sections and incubated for $10 \mathrm{~min}$ at room temperature. The sections were then stained by $0.05 \%$ DAB staining solution (Leica Microsystems, Inc.) at room temperature for $15 \mathrm{~min}$ and stained with $2 \mathrm{~g} / 1$ hematoxylin (Beijing Solarbio Science $\&$ Technology Co., Ltd.) for $3 \mathrm{~min}$ at room temperature. The sections were then observed using an MF43 fluorescence microscope (Guangzhou Micro-shot Technology Co., Ltd.), with magnification of x100 and 200.

Cell culture. Colorectal cancer HT-29, LoVo, SW-480, SW-620, Caco2, HCT-116, HCT-15, RKO, LS174T and DLD-1 cell lines, and the normal colon CCD-18Co cell line were purchased from American Type Culture Collection. RPMI-1640 medium containing 2 mM L-glutamine, $10 \%$ fetal bovine serum (FBS), penicillin $\mathrm{G}(100 \mathrm{U} / \mathrm{ml})$ and streptomycin $(0.1 \mathrm{mg} / \mathrm{ml})$ was used as cell culture medium and cultured with the cells at $37^{\circ} \mathrm{C}$ with $5 \% \mathrm{CO}_{2}$. All culture reagents were purchased from Gibco; Thermo Fisher Scientific, Inc. HT-29 cells were inoculated and grown to $80 \%$ confluency prior to treatment with adequate concentrations of rapamycin $(10 \mathrm{nM}$; cat. no. V900930; Sigma-Aldrich; Merck KGaA) and 5-aminoimidazole-4-carboxamide ribonucleotide (AICAR; $2 \mathrm{mM}$; cat. no. A9978; Sigma-Aldrich; Merck KGaA) for $90 \mathrm{~min}$, and the cells were then transfected with KLK12 plasmid for 12, 24 and $48 \mathrm{~h}$ to detect cell viability.

Transfection. $50 \mathrm{nmol} / \mathrm{l}$ small interfering RNA targeted KLK12 (siKLK12) and negative siRNA (Shanghai GenePharma Co., Ltd.) were inserted into pLKO.1-TRC vector (Shanghai Institute of Biochemistry and Cell Biology, Chinese Academy of Sciences) to produce the recombinant plasmid. siRNA was used to transfect HT-29 cells using Lipofectamine ${ }^{\mathrm{TM}} 2000$ (Invitrogen; Thermo Fisher Scientific, Inc.). The KLK12 coding region was inserted into the pLKO.1-TRC vector, and the HT-29 cells were transfected with KLK12 plasmid or empty vector. The cells that did not undergo transfection were used as a control. Sequences of the siRNAs used in the present study were as follows: KLK12 siRNA sense, 5'-AAACAGUGA CAGCCACGUATT-3'; KLK12 siRNA antisense, 5'-UACGUG GCUGUCACUGUUUGG-3'; negative siRNA sense, 5'-UUC UCCGAACGUGUCACGUTT-3'; negative siRNA antisense, 5'-ACGUGACACGUUCGGAGAATT-3'. Transfected cells were cultured in complete medium for $48 \mathrm{~h}$ prior to use in the invasion, migration and apoptosis experiments. 
Table I. Primers for reverse transcription quantitative polymerase chain reaction.

\begin{tabular}{lll}
\hline Genes & \multicolumn{1}{c}{ Forward } & Reverse \\
\hline KLK12 & GCCTCAACCTCTCCATCGTC & CTTGAAGGACTCCCCCACAC \\
E-cadherin & CGAGAGCTACACGTTCACGG & GGGTGTCGAGGGAAAAATAGG \\
Vimentin & TGCCGTTGAAGCTGCTAACTA & CCAGAGGGAGTGAATCCAGATTA \\
Snail & TCGGAAGCCTAACTACAGCGA & AGATGAGCATTGGCAGCGAG \\
MMP-2 & TTGATGGCATCGCTCAGATC & TTGTCACGTGGCGTCACAGT \\
MMP-9 & GACGCAGACATCGTCATCCA & CACAACTCGTCATCGTCGAAA \\
GAPDH & AACGTGTCAGTGGTGGACCTG & AGTGGGTGTCGCTGTTGAAGT
\end{tabular}

KLK12, kallikrein-related peptidase 12; E-cadherin, epithelial cadherin; MMP, matrix metalloproteinase.

MTT assay. HT-29 cells were transfected with or without exposure to AICAR/rapamycin. The transfected cells were seeded in 96 -well plates at a density of $5 \times 10^{3} / 1$. Following incubation at $37^{\circ} \mathrm{C}$ for 12,24 and $48 \mathrm{~h}, 10 \mu \mathrm{l}$ MTT solution $(5 \mathrm{mg} / \mathrm{ml})$ was added into the wells and the plate was incubated in an atmosphere containing $5 \% \mathrm{CO}_{2}$ at $37^{\circ} \mathrm{C}$ for $4 \mathrm{~h}$. Next, a microplate reader was used to measure the absorbance at $450 \mathrm{~nm}$. Cell viability was detected by MTT assay (Thermo Fisher Scientific, Inc.) according the manufacturer's protocol.

Wound healing assay. After $48 \mathrm{~h}$ of cell culture transfection, the cell density of each group was $\sim 90 \%$. The cells were serum-starved for $24 \mathrm{~h}$, and $200 \mu \mathrm{l}$ sterile tip was used to scratch the cells in the well plate. The medium was discarded and the surface was gently washed 3 times with PBS to rinse off the exfoliated cells. After 0 and $24 \mathrm{~h}$, the cell culture plate was placed under a 40-fold inverted microscope (Olympus Corporation) to be observed, and images at the same position were captured twice.

Transwell assay. Transwell chambers (8 $\mu \mathrm{m}$; Corning Incorporated) was placed on a 24-well plate with a layer of $50 \mu 1$ Matrigel (BD Biosciences) coated onto the Transwell chamber $37^{\circ} \mathrm{C}$ for $30 \mathrm{~min}$. Then, $6 \times 10^{4}$ transfected cells were cultured in serum-free medium for $12 \mathrm{~h}$ to eliminate the effects of the serum and then resuspended in RPMI-1640 medium without FBS. A total of $100 \mu \mathrm{l}$ suspended cells were added to the Transwell chamber, while $400 \mu 1$ RPMI-1640 medium containing $20 \%$ FBS was added to the lower chambers. The cells were cultured with $5 \% \mathrm{CO}_{2}$ for $24 \mathrm{~h}$ at $37^{\circ} \mathrm{C}$ in an incubator. The Transwell chamber was then removed, the culture solution in the Transwell plate was discarded and washed with calcium-free PBS twice, and the chamber was fixed in $100 \%$ methanol solution at $4^{\circ} \mathrm{C}$ for $30 \mathrm{~min}$ and stained with $0.1 \%$ crystal violet for $20 \mathrm{~min}$ at room temperature. Next, PBS was used to wash the chamber, and the upper chamber liquid was aspirated. The unmigrated cells in the upper layer were gently wiped off using a cotton swab. The microporous membrane was removed using a small tweezers carefully and dried with the bottom side up and then transferred to a glass slide, sealed with a neutral gum. Images were observed and captured using an inverted light microscope (Olympus Corporation), with the magnification of $\mathrm{x} 200$.
Apoptosis assay. An Annexin V-fluorescein isothiocyanate (FITC)/propidium iodide (PI) apoptosis detection kit (BD Biosciences Medical Devices Shanghai Co., Ltd.) was used to detect HT-29 cells apoptosis. Colorectal cancer HT-29 cells $\left(5 \times 10^{5}\right.$ cells per well) were seeded in 6 -well plates until cell density reached $85 \%$. siKLK12, KLK12 plasmids and the corresponding control plasmids were used to transfect HT-29 cells, which were then cultured in serum-free medium at $37^{\circ} \mathrm{C}$ for $5 \mathrm{~h}$. After $48 \mathrm{~h}$ of culture, the cells were centrifuged at $4^{\circ} \mathrm{C}$ for $10 \mathrm{~min}$, at the speed of 5,000 x g, and washed twice with PBS, and $100 \mu 11 \mathrm{X}$ Annexin V Binding Buffer and $5 \mu \mathrm{l}$ FITC-labeled Annexin V $(20 \mu \mathrm{g} / \mathrm{ml})$ were added to the cells and incubated at room temperature for $20 \mathrm{~min}$. Next, the cells were added with $5 \mu \mathrm{l}$ PI $(50 \mu \mathrm{g} / \mathrm{ml})$ for $5 \mathrm{~min}$ and $400 \mu \mathrm{l}$ binding buffer (BD Biosciences). A flow cytometer (BD Biosciences Medical Devices Shanghai Co., Ltd.) was used to analyze cell apoptosis; among those cells, FITC-/PI- cells represented healthy living cells, $\mathrm{FITC}^{-} / \mathrm{PI}^{+}$cells represented necrotic cells, FITC ${ }^{+} / \mathrm{PI}^{-}$cells indicated early apoptotic cells, $\mathrm{FITC}^{+} / \mathrm{PI}^{+}$cells represented late apoptotic cells.

Reverse transcription quantitative polymerase chain reaction (RT-qPCR). Following transfection, HT-29 cells were incubated in an incubator for $48 \mathrm{~h}$, and total RNA from HT-29 cells $\left(2 \times 10^{4}\right.$ cells/well in 6 -well plates) and $50 \mathrm{mg}$ of colorectal cancer and normal tissues were extracted using TRIzol ${ }^{\circledR}$ reagent (Thermo Fisher Scientific, Inc.) according to the manufacturer's protocol. NanoDrop ${ }^{\mathrm{TM}} 2000$ spectrophotometer (NanoDrop Technologies; Thermo Fisher Scientific, Inc.) was conducted to measure RNA quality; an A260/A280 ratio between 1.8-2.0 was required for the generation of cDNA. The oligo-dT or stem-loop reverse transcriptase primers (Takara Bio, Inc.) were used to obtain cDNA, and the RT thermocycler conditions were set at $42^{\circ} \mathrm{C}$ for $60 \mathrm{~min}, 70^{\circ} \mathrm{C}$ for $5 \mathrm{~min}$ and maintenance at $4^{\circ} \mathrm{C}$. qPCR was performed with $\mathrm{SYBR}^{\circledR}{ }^{\circledR}$ Premix Ex Taq ${ }^{\mathrm{TM}}$ II (Takara Bio Inc.) using real-time PCR Detection System (ABI 7500; Thermo Fisher Scientific, Inc.). PCR reaction conditions were as follows: Pretreatment at $95^{\circ} \mathrm{C}$ for $10 \mathrm{~min}$, followed by 40 cycles at $94^{\circ} \mathrm{C}$ for $15 \mathrm{sec}, 60^{\circ} \mathrm{C}$ for $1 \mathrm{~min}$ and $60^{\circ} \mathrm{C}$ for $1 \mathrm{~min}$, and preservation at $4^{\circ} \mathrm{C}$. The $2^{-\Delta \Delta \mathrm{Cq}}$ method was used to quantify the data (21). The primers used in this assay are listed in Table I.

Western blot analysis. The HT-29 cells were treated with siKLK12, KLK12 and the corresponding control plasmid and 
A

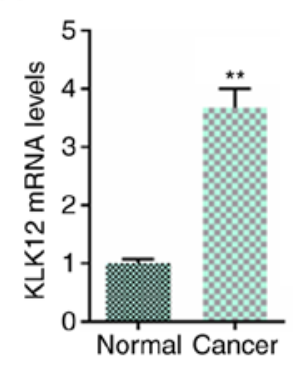

B

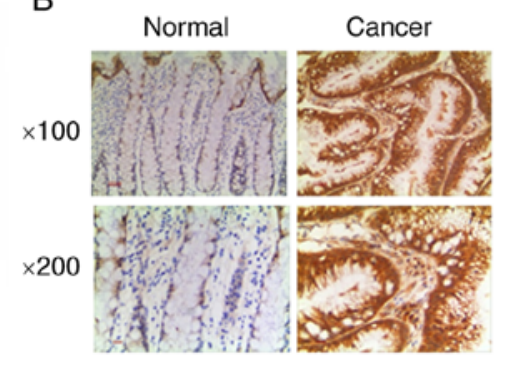

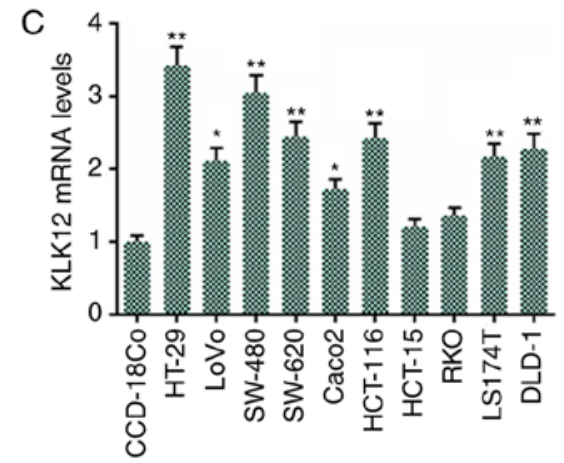

Figure 1. KLK12 is highly expressed in colorectal cancer tissues and cell lines. (A) RT-qPCR analysis of mRNA expression levels of KLK12 in colorectal cancer tissues and normal tissues. (B) Immunohistochemistry was used to detect the expression of KLK12 in colorectal cancer and normal tissues. (C) RT-qPCR analysis of mRNA expression of KLK12 in colorectal cancer cell lines and normal colorectal cells. ${ }^{*} \mathrm{P}<0.05$ and ${ }^{* * *} \mathrm{P}<0.01$ vs. normal or CCD-18Co cells. KLK12, Kallikrein-related peptidase 12; RT-qPCR, reverse transcription quantitative polymerase chain reaction.

then cultured in an incubated for $48 \mathrm{~h}$. Total proteins were extracted from HT-29 cells $\left(2 \times 10^{4}\right.$ cells/well in 6-well plates) and tissues $(50 \mathrm{mg}$ ) by radioimmunoprecipitation assay lysis buffer (Cell Signaling Technology, Inc.). A BCA Protein Assay kit (Pierce; Thermo Fisher Scientific, Inc.) was applied to measure the concentrations of proteins, which were adjusted to a concentration of $6 \mu \mathrm{g} / \mu \mathrm{l}$ using $1 \mathrm{X}$ loading and DEPC water. The samples $(5 \mu \mathrm{l})$ were separated by $10 \%$ SDS-PAGE gels and then transferred to polyvinylidene fluoride membrane (PVDF; EMD Millipore). Following blocking in 5\% nonfat milk in PBST (0.1\% Tween-20 in PBS) for $1 \mathrm{~h}$ at $37^{\circ} \mathrm{C}$, the PVDF membranes were probed with the primary antibodies overnight at $4^{\circ} \mathrm{C}$, followed washing 3 times with PBST. Next, the membrane was incubated with the secondary antibody (horseradish peroxidase-conjugated goat anti-mouse/rabbit IgG, 1:2,000; cat. nos. sc-516102/sc-2357; Santa Cruz Biotechnology, Inc.) at room temperature for $2 \mathrm{~h}$ and washed with PBST 3 times. An EZ-ECL kit (Biological Industries) was used to develop the membranes, and the gray values of the bands were analyzed and quantified using ImageJ v5.0 software (Bio-Rad Laboratories, Inc.). The antibodies used in the study were as follows: Anti-GAPDH (mouse; 1:1,000; cat. no. LS-B1625; LifeSpan BioSciences, Inc.); anti-epithelial (E)-cadherin (mouse; 1:1,000; cat. no. ab1416; Abcam); anti-vimentin (rabbit; 1:1,000; cat. no. ab92547; Abcam); anti-matrix metalloproteinase (MMP)-2 (rabbit; 1:1,000; cat. no. ab37150; Abcam); anti-MMP-9 (rabbit; 1:1,000; cat. no. ab73734; Abcam); anti-zinc finger protein SNAI1 (Snail; rabbit; 1:1,000; cat. no. 3879; Cell Signaling Technology, Inc.); anti-cleaved caspase-3 (rabbit; 1:1,000; cat. no. ab13847; Abcam); anti-Bax (rabbit; 1:1,000; cat. no. ab32503; Abcam); anti-Bcl-2 (rabbit; 1:1,000; cat. no. ab32124; Abcam); anti-AMPK (mouse; 1:1,000; cat. no. ab32047; Abcam); anti-phosphorylated (p)-AMPK (rabbit; 1:1,000; cat. no. ab133448; Abcam); anti-mTOR (rabbit; 1:1,000; cat. no. ab32028; Abcam); and anti-p-mTOR (rabbit; 1:1,000; cat. no. ab84400; Abcam).

Statistical analysis. All the experimental data are presented as the mean \pm standard deviation. Statistical analyses were performed using GraphPad Prism 6 (GraphPad Software, Inc.) statistical software. A one-way analysis of variance followed by Turkey's post hoc was used to analyze differences among the experimental groups. $\mathrm{P}<0.05$ was considered to indicate a statistically significant difference.

\section{Results}

KLK12 is highly expressed in colorectal cancer tissues and cell lines. In the present study, the expression levels of KLK12 in colorectal cancer tissues and adjacent normal tissues of cancer were initially explored using RT-qPCR. The results indicated that the KLK12 mRNA level was increased in the cancer tissues compared with the adjacent normal tissues (Fig. 1A). The IHC results indicated a large number of brown particles in the cancer tissues (Fig. 1B). Next, the KLK12 levels in the colorectal cancer cell lines and normal cells were determined using RT-qPCR; the results in the cell lines were consistent with those from the cancer tissues, in that the KLK12 mRNA levels were identified to be increased at different degrees in the majority of the colorectal cancer cell lines, with the exception of HCT-15 and RKO cells, compared with normal colorectal cells CCD-18Co (Fig. 1C). HT-29 cells exhibited the highest expression of KLK12; therefore, HT-29 cells were selected to be used in the following experiments.

Knockdown of KLK12 inhibits HT-29 cells viability and promotes the cell apoptosis. To further investigate the functional effects of KLK12 on colorectal cancer HT-29 cells, KLK12 expression was silenced by siRNA using Lipofectamine ${ }^{\circledR} 2000$ transfection reagent, and RT-qPCR (Fig. 2A) and western blot analysis (Fig. 2B and C) were performed to confirm that the transfection was successful. Subsequently, HT-29 cells were seeded in a 96-well plate and transfected with small interfering RNA of KLK12 for 12, 24 and 48 h. The viability of HT-29 cells was analyzed using the MTT assay. It was identified that knockdown of KLK12 significantly decreased the viability of HT-29 cells at 24 and 48 h (Fig. 2D). Furthermore, cell apoptosis levels were quantified by flow cytometry using Annexin V and PI double staining, and it was demonstrated that KLK12 silencing noticeably increased the proportion of apoptotic HT-29 cells compared with the control and NC groups (Fig. 2E).

Knockdown of KLK12 inhibits HT-29 cells migration and invasion. Migration and invasion are typical biological characteristics of malignant tumors; therefore, invasion and migration were determined by wound healing and Transwell invasion assays, respectively. It was observed that KLK12 silencing for $24 \mathrm{~h}$ significantly decreased the migration rate in 


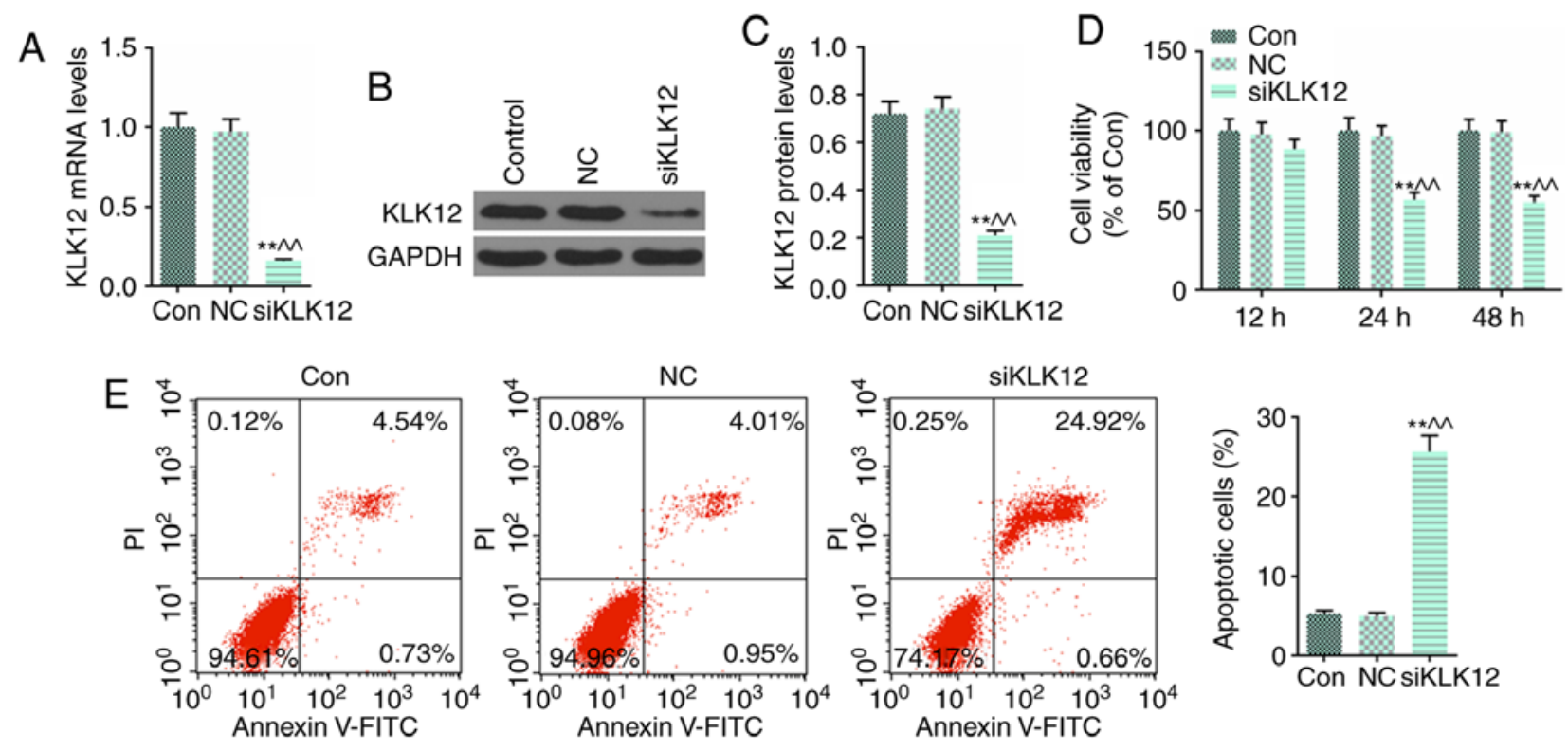

Figure 2. Knockdown of KLK12 inhibits HT-29 cell viability and promotes cell apoptosis. (A) The transfection efficiency of KLK12 mRNA level was confirmed by reverse transcription quantitative polymerase chain reaction. (B and C) The transfection efficiency of KLK12 protein level was (B) verified and (C) quantified by western blot analysis. (D) Analysis of cell viability using the Cell Counting Kit-8 assay in HT-29 cells treated with or without siKLK12 or NC. (E) Flow cytometry was used to detect HT-29 cells apoptosis with or without siKLK12 or NC. ${ }^{* *} \mathrm{P}<0.01$ vs. control group. ${ }^{\wedge} \mathrm{P}<0.01$ vs. NC group. KLK12, kallikrein-related peptidase 12; si, small interfering RNA; NC, negative control; con, control.

HT-29 cells (Fig. 3A and B). Concomitantly, cell invasion was inhibited following $24 \mathrm{~h}$ downregulation of KLK12 in HT-29 cells (Fig. 3C and D).

Overexpression of KLK12 suppresses apoptosis in HT-29 cells. The expression level of KLK12 was overexpressed by a KLK12 plasmid using Lipofectamine ${ }^{\circledR} 2000$ transfection reagent, and RT-qPCR (Fig. 4A) and western blot analysis (Fig. 4B and C) were performed to confirm that the transfection was successful. Subsequently, HT-29 cells were seeded in a 96-well plate and transfected with the KLK12 plasmid for 12, 24 and $48 \mathrm{~h}$. The viability of the HT-29 cells was analyzed using the MTT assay. KLK12 overexpression significantly increased the viability of HT-29 cells at $48 \mathrm{~h}$ (Fig. 4D). Furthermore, cell apoptosis levels were quantified by flow cytometry with Annexin V and PI double staining, and it was identified that KLK12 overexpression significantly decreased the proportion of apoptotic HT-29 cells compared with the control and mock groups (Fig. 4E).

Upregulation of KLK12 promotes migration and invasion in $H T-29$ cells. In the present study, invasion and migration were determined by wound healing and Transwell invasion assays, respectively. The results demonstrated that overexpressing KLK12 for $24 \mathrm{~h}$ significantly increased the migration rate of HT-29 cells (Fig. 5A and B), and that cell invasion was also increased following KLK12 upregulation for $24 \mathrm{~h}$ in the HT-29 cells (Fig. 5C and D).

EMT-associated and apoptosis-associated proteins are altered in HT-29 cells treated with siKLK12/KLK12. The effects of siKLK12/KLK12 on the EMT-associated proteins including E-cadherin, Vimentin, Snail, MMP-2 and MMP-9 were determined in HT-29 cells by performing RT-qPCR and western blot analysis. It was identified that treatment with KLK12
siRNA significantly upregulated the expression of E-cadherin and downregulated the expression levels of vimentin, Snail, MMP-2 and MMP-9 at mRNA levels (Fig. 6A) and protein levels (Fig. 6B and C). However, overexpression of KLK12 produced the opposite effect in these proteins, in comparison with the results from siKLK12 treatment (Fig. 6A-C). It was also identified that apoptosis was induced by siKLK12 treatment and inhibited by KLK12 overexpression from the results of flow cytometry; however, alterations to the apoptosis-associated proteins remained unclear. Therefore, the effects of KLK12 silencing and overexpression on the expression of apoptosis-association proteins including Bcl-2, Bax and cleaved caspase-3 was examined in the HT-29 cells by western blot analysis. The results indicated that KLK12 silencing induced apoptosis, as the expression of anti-apoptosis protein $\mathrm{Bcl} 2$ was significantly downregulated and the expression levels of pro-apoptosis proteins Bax and cleaved caspase-3 were upregulated, when compared with the control group (Fig. 6D and E), while overexpression of KLK12 elicited the opposite effect in these proteins, in comparison with the effects of siKLK12 treatment (Fig. 6D and E).

AMPK and mTOR pathways are involved in HT-29 cells treated with siKLK12/KLK12. The AMPK/mTOR signaling pathway serves an important role in tumor progression and metastasis. To explore the potential mechanism of KLK12 in the regulation of colorectal cancer cell migration and invasion, the present study examined the effects of KLK12 on AMPK/mTOR signaling. The levels of p-AMPK, AMPK, p-mTOR and mTOR in the HT-29 cells, which were transfected with siKLK12 and the KLK12 plasmid, were determined by western blot analysis. The results demonstrated that in HT-29 cells transfected with siKLK12, p-AMPK levels were significantly upregulated compared with control group; by contrast, the expression of p-mTOR was decreased (Fig. 7A and B). However, overexpression of KLK12 
A
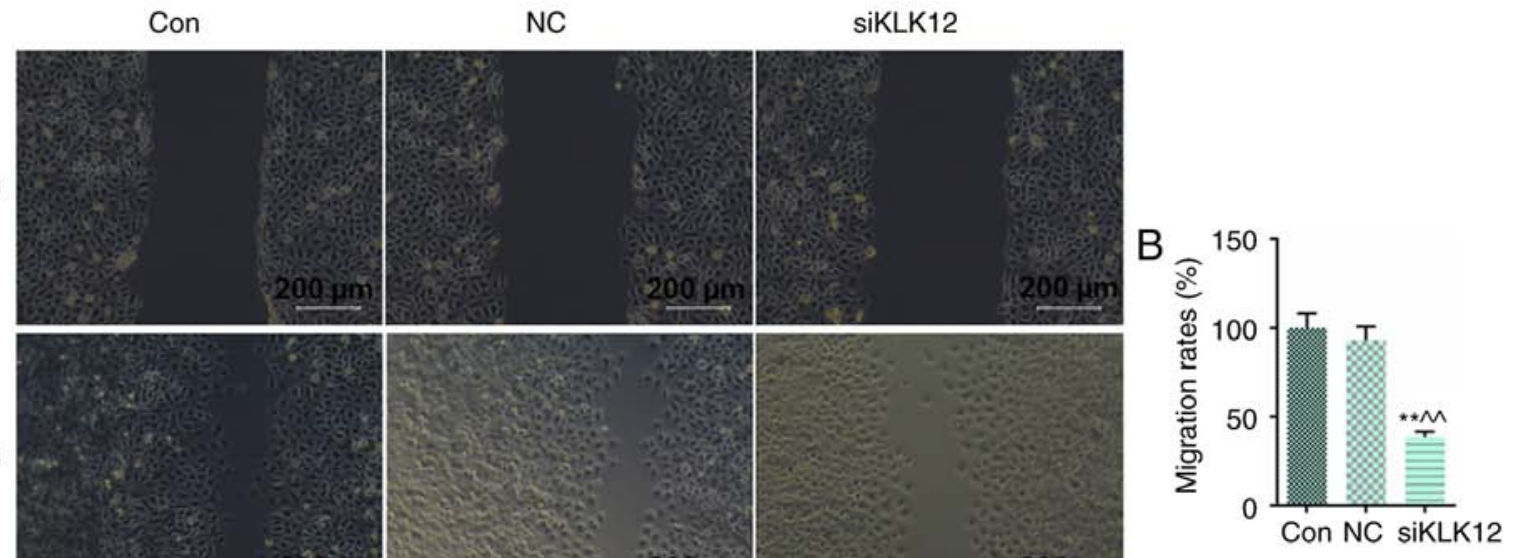

$24 \mathrm{~h}$
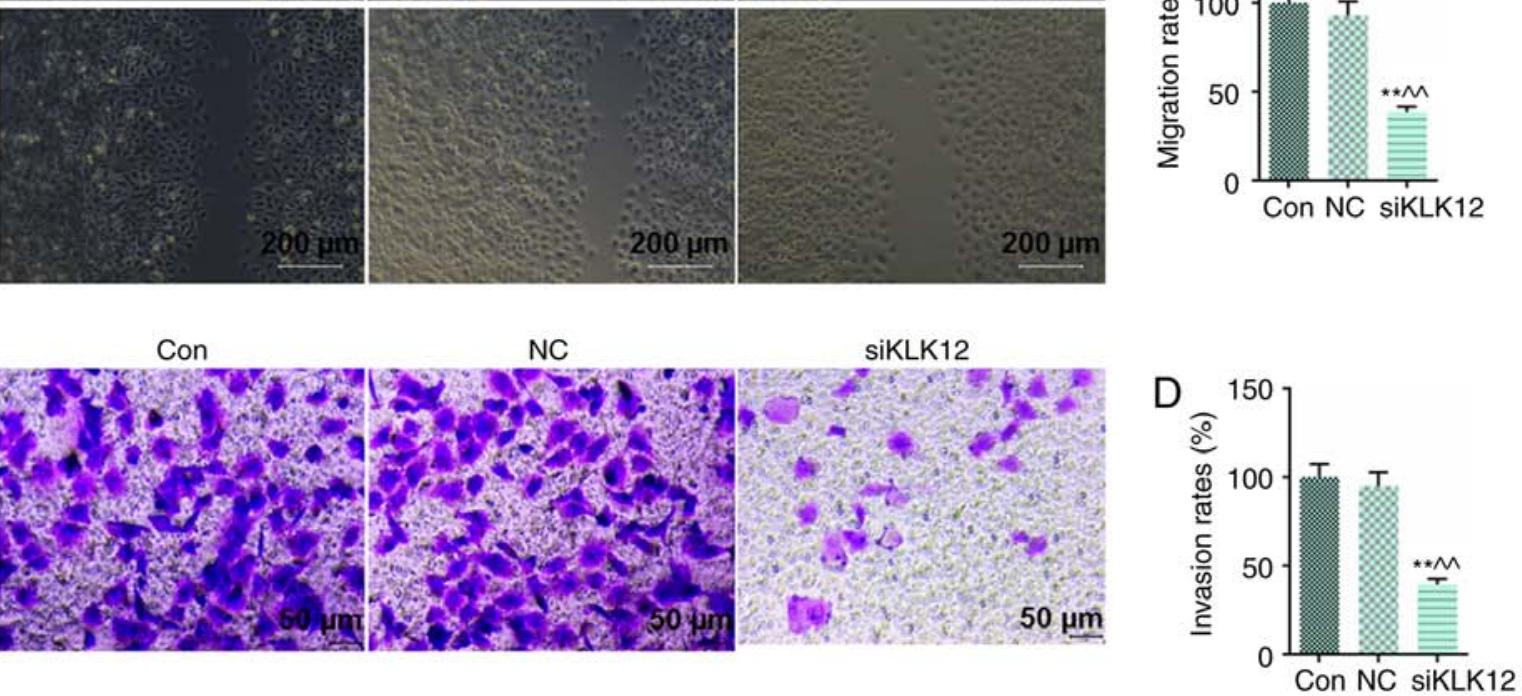

Figure 3. Migration and invasion are inhibited by KLK12 silencing in HT-29 cells. (A and B) The migration rate of HT-29 cells treated with siKLK12 for 0 and $24 \mathrm{~h}$ were (A) visualize and (B) quantified using a wound healing assay. (C and D) Invasion rate of HT-29 cells treated with siKLK12 for $24 \mathrm{~h}$ were (C) visualized and (D) quantified using a Transwell assay. ${ }^{* *} \mathrm{P}<0.01$ vs. control group. ${ }^{\wedge} \mathrm{P}<0.01$ vs. NC group. KLK12, kallikrein-related peptidase 12 ; NC, negative control; con, control.
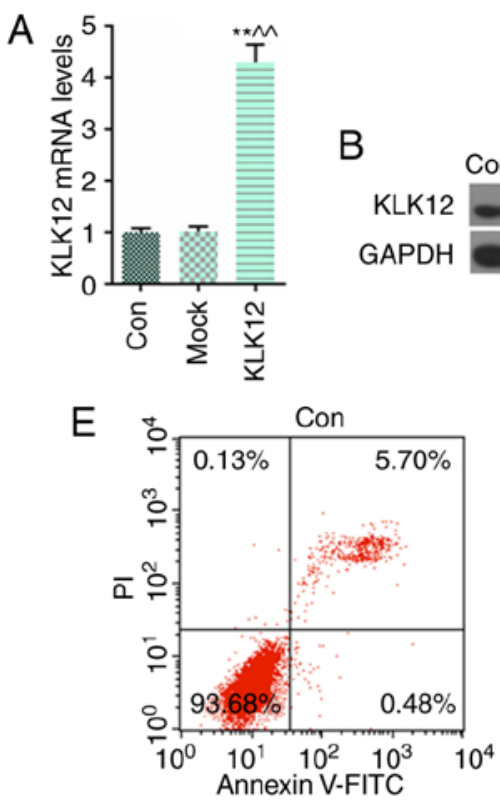

B
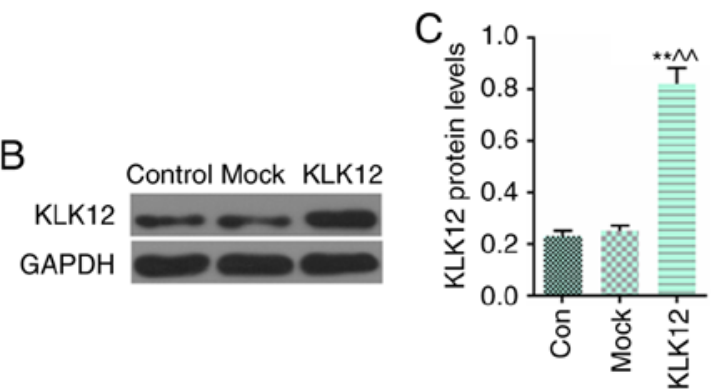

$\mathrm{D}=150$ Con

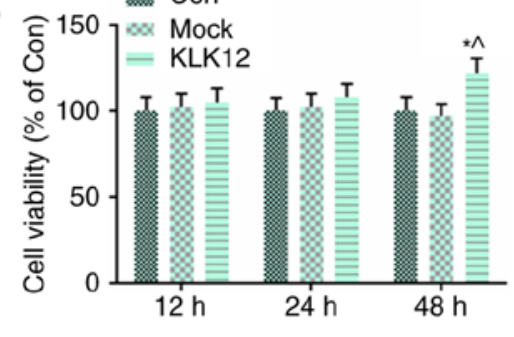

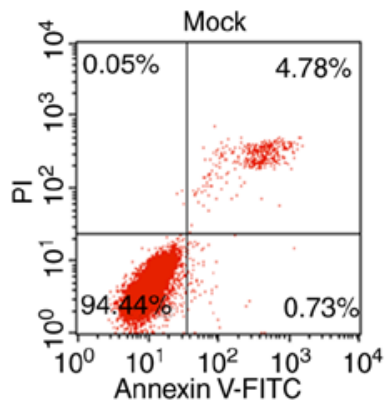
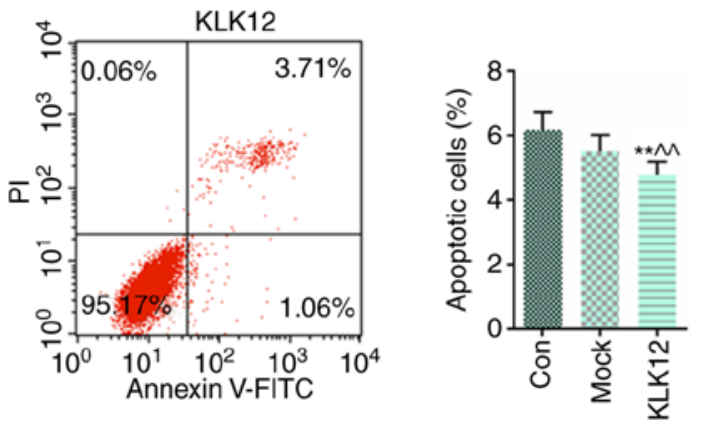

Figure 4. Overexpression of KLK12 suppresses apoptosis in HT-29 cells. (A) The transfection efficiency of KLK12 mRNA level was confirmed by reverse transcription quantitative polymerase chain reaction. (B and C) The transfection efficiency of KLK12 protein level was (B) verified and (C) quantified by western blot analysis. (D) Analysis of cell viability using the Cell Counting Kit-8 assay in HT-29 cells treated with or without KLK12 or NC plasmid. (E) Flow cytometry was used to detect HT-29 cells apoptosis with or without KLK12 or NC plasmid treatment. ${ }^{*} \mathrm{P}<0.05$ and ${ }^{* *} \mathrm{P}<0.01$ vs. control group. ${ }^{\wedge} \mathrm{P}<0.05$ and ${ }^{\wedge} \mathrm{P}<0.01$ vs. mock group. KLK12, kallikrein-related peptidase 12; Con, control.

resulted in the opposite effect in those proteins compared with siKLK12 treatment (Fig. 7A and B). In order to confirm the role of AMPK/mTOR in the progression of HT-29 cells, an activator of the AMPK signaling pathway, AICAR (2 mM), and a specific inhibitor of mTOR signaling pathway, rapamycin $(10 \mathrm{nM})$, were incubated with HT-29 cells with or without the KLK12 

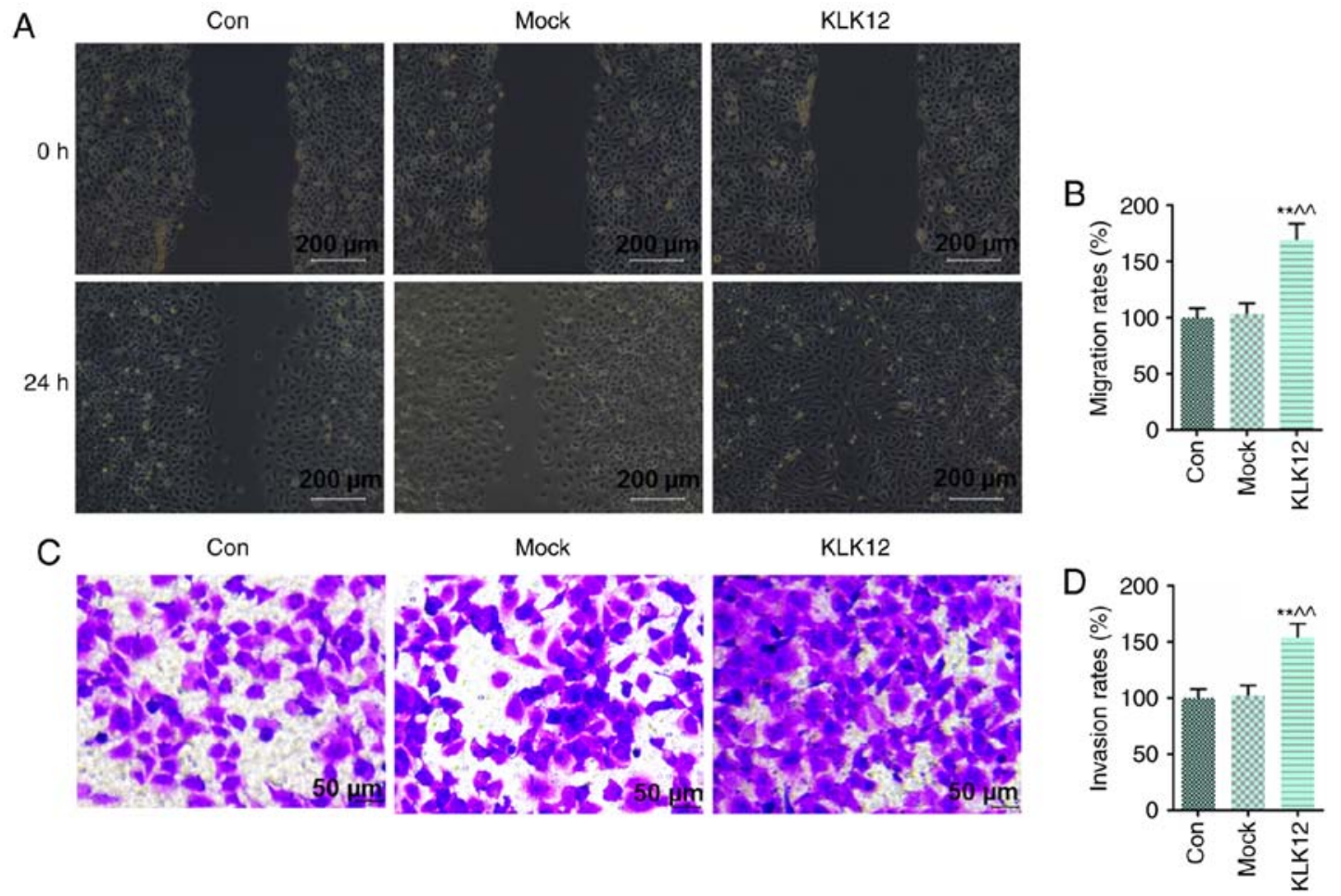

Figure 5. Migration and invasion are promoted by KLK12 overexpression in HT-29 cells. (A and B) Migration rate of HT-29 cells treated with KLK12 plasmid for 0 and $24 \mathrm{~h}$ were (A) visualized and (B) quantified using a wound healing assay. (C and D) Invasion rate of HT-29 cells treated with KLK12 plasmid for $24 \mathrm{~h}$ were (C) visualized and (D) quantified using a Transwell assay. ${ }^{* *} \mathrm{P}<0.01$ vs. control group. ${ }^{\wedge} \mathrm{P}<0.01$ vs. mock group. KLK12, kallikrein-related peptidase 12 ; con, control.
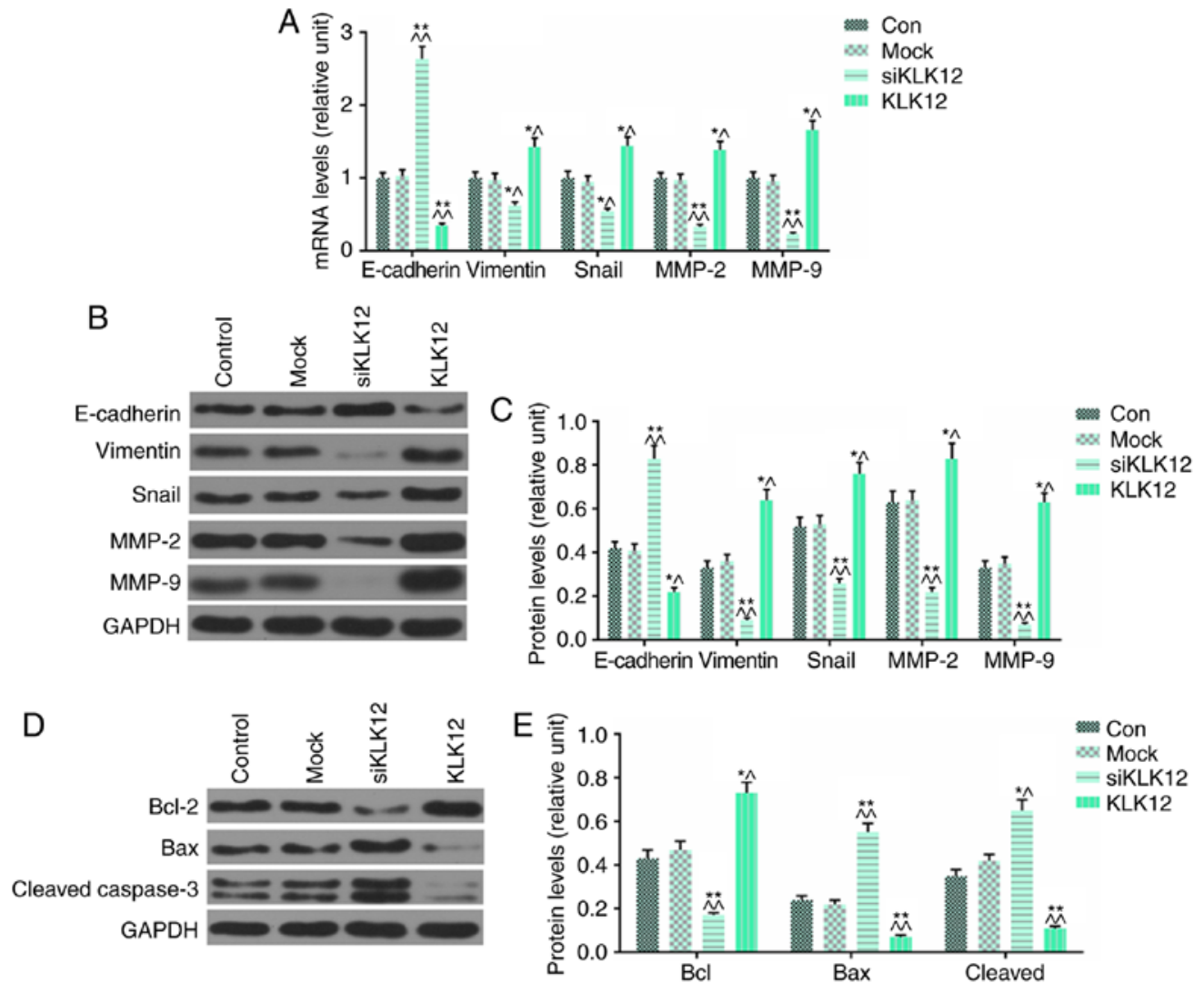

Figure 6. Expression of epithelial-mesenchymal transition-associated and apoptosis-associated proteins is altered in HT-29 cells treated with siKLK12 or KLK12 overexpression plasmids. (A) The mRNA levels of E-cadherin, vimentin, Snail, MMP-2 and MMP-9 were analyzed by reverse transcription quantitative polymerase chain reaction. (B and C) The protein levels of E-cadherin, vimentin, Snail, MMP-2 and MMP-9 were analyzed by western blot analysis (D and E) The protein levels of Bcl-2, Bax protein and cleaved caspase- 3 were analyzed by western blot analysis. ${ }^{*} \mathrm{P}<0.05$ and ${ }^{* * *} \mathrm{P}<0.01$ vs. NC group. ${ }^{\wedge} \mathrm{P}<0.05$ and ${ }^{\wedge} \mathrm{P}<0.01$ vs. mock group. The 'KLK12' group represents the KLK12 overexpression group. KLK12, kallikrein-related peptidase 12; si, small interfering RNA; E-cadherin, epithelial cadherin; Snail, zinc finger protein SNAI1; MMP, matrix metalloproteinase; NC, negative control. 
A

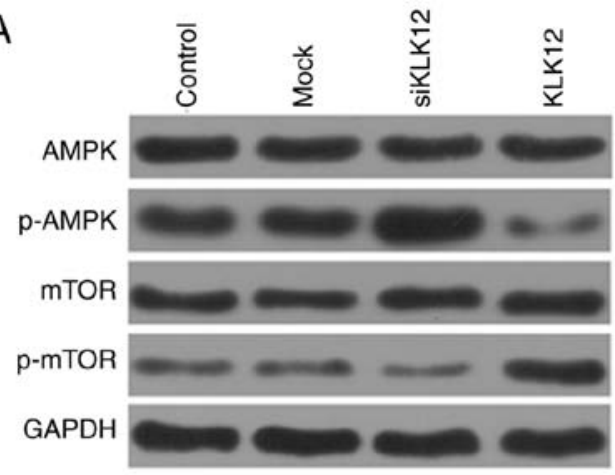

B

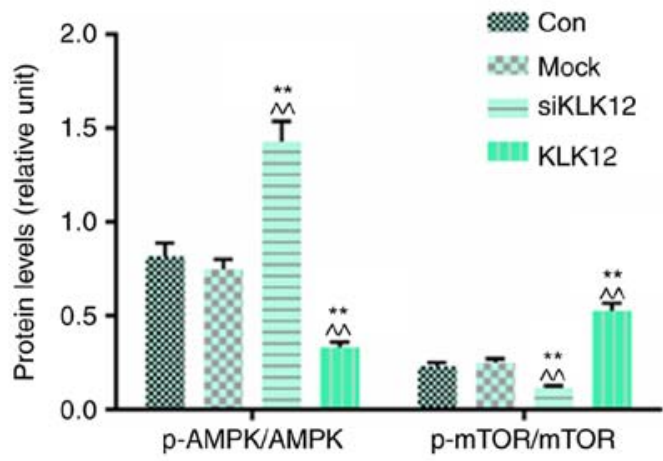

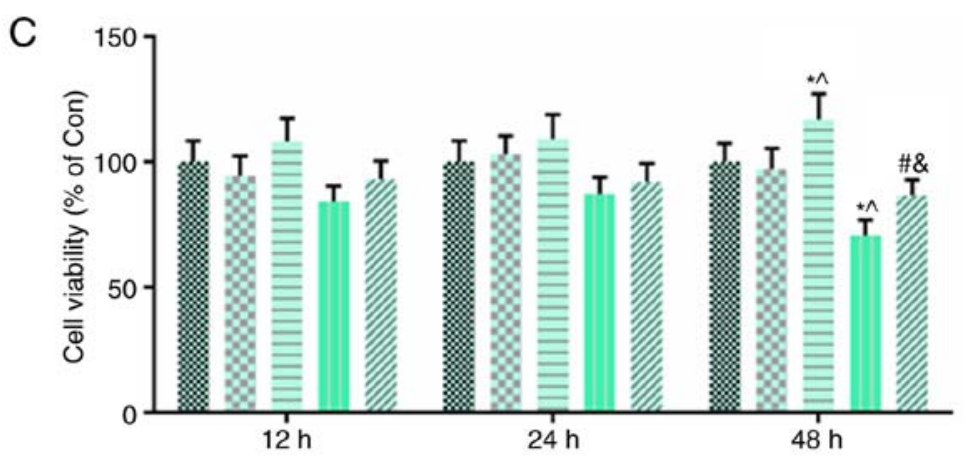

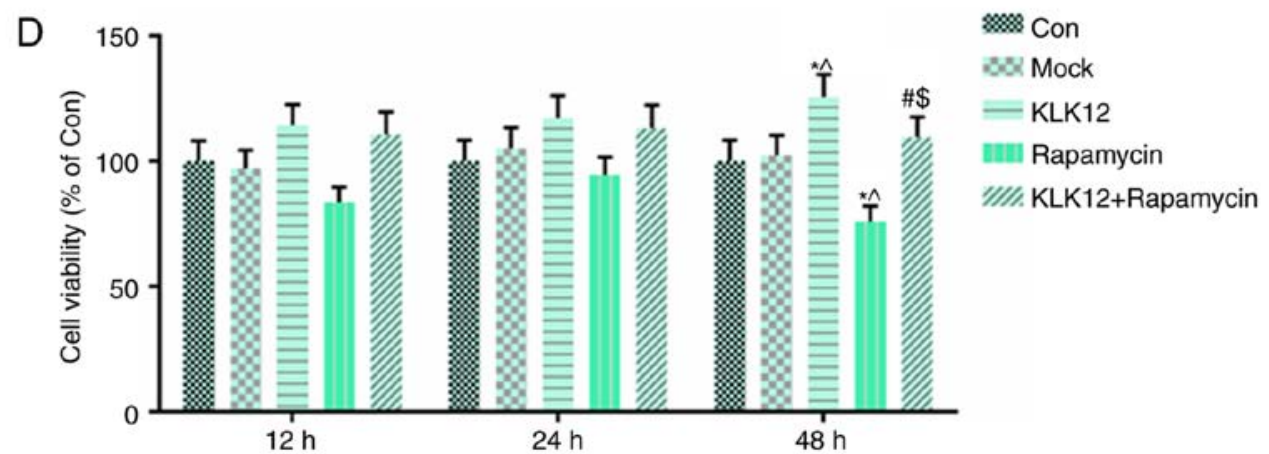

Figure 7. AMPK and mTOR pathways are involved in HT-29 cells treated with siKLK12 or KLK12 overexpression plasmids. (A and B) Protein levels of AMPK, p-AMPK, mTOR, p-mTOR and GAPDH in HT-29 cells were (A) analyzed and (B) quantified by western blot analysis. (C) Analysis of cell viability using the CCK-8 assay in mock or KLK12-transfected HT-29 cells incubated with or without AICAR treatment. (D) Analysis of cell viability using the CCK-8 assay in mock or KLK12-transfected HT-29 cells incubated with or without rapamycin treatment. ${ }^{*} \mathrm{P}<0.05$ and ${ }^{* *} \mathrm{P}<0.01$ vs. NC group. ${ }^{\wedge} \mathrm{P}<0.05$ and ${ }^{\wedge \wedge} \mathrm{P}<0.01$ vs. mock group. ${ }^{~} \mathrm{P}<0.05$ vs. KLK12. ${ }^{\circledR} \mathrm{P}<0.05$ vs. AICAR. ${ }^{5} \mathrm{P}<0.05$ vs. rapamycin. The 'KLK12' group represents the KLK12 overexpression group. KLK12, kallikrein-related peptidase 12 ; AMPK, adenosine monophosphate-activated protein kinase; p-APMK, phosphorylated adenosine monophosphate-activated protein kinase; mTOR, mammalian target of rapamycin; p-mTOR, phosphorylated mammalian target of rapamycin; CCK-8, Cell Counting Kit-8; AICAR, 5-aminoimidazole-4-carboxamide ribonucleotide.

plasmid for 12, 24 and $48 \mathrm{~h}$. The viability of the HT-29 cells was analyzed using MTT assay. The data demonstrated that AICAR reversed the effect of KLK12 overexpression on cell viability, and that AICAR had significant inhibitory effect on viability of HT-29 cells (Fig. 7C). Surprisingly, the results of rapamycin on the effect of KLK12 on HT-29 cell viability were consistent with AICAR (Fig. 7D).

\section{Discussion}

Tissue or serum levels of KLK are examined individually or in small groups as a diagnostic or prognostic factor for determining different types of cancer $(22,23)$. In the colorectal cancer, KLK has been demonstrated to act as a diagnostic or prognostic factor (16). However, KLK12 has not been studied extensively in colorectal cancer. In the present study, KLK12 overexpression was demonstrated promoting the viability and inhibit apoptosis in the colorectal cancer-derived HT29 cell line via the activation of the AMPK/mTOR signaling pathways.

There have been multiple previous studies concerning KLK12 in different types of cancer: Li et al identified that KLK12 levels were significantly increased in gastric cancer cells compared with in GES-1 cells (24). In addition, analysis of a combined sample of 3,153 cases and 3,199 controls indicated that the KLK12 tag single nucleotide polymorphism rs3865443 was marginally and statistically correlated with the risk of developing prostate cancer (25). KLK12 expression at mRNA level was markedly increased in MKN-45 gastric cancer cells compared with normal mucosal cells and 2 other gastric cancer cell lines (26); the mRNA level of KLK12 observed in the present study was consistent with previous studies. It was also identified that KLK12 expression levels were increased in colorectal cancer tissues and colorectal cancer-derived cell lines compared with their corresponding controls. These 
data demonstrated that the oncogenic potential of KLK12 in colorectal cancer was similar to that in other types of cancer.

Metastasis is regarded as a major factor contributing to the poor prognosis of patients with colorectal cancer and is a typical feature of malignant tumors. Overexpression of KLK12 protein was significantly associated with lymph node metastasis, and the proliferation of gastric cancer MKN-45 cells was markedly decreased by the knockdown of KLK12 protein (26).

Transfection of AGS cells with KLK12 siRNA led to decreased cell proliferation (24). KLK12 efficiently cleaved human extracellular matrix proteins fibronectin and tenascin, both of which are involved in the regulation of endothelial cell adhesion and migration (27). In the present study, cell viability, migration and invasion were inhibited when the HT-29 cells were transfected with siKLK12. Concomitantly, E-cadherin expression was upregulated and vimentin, Snail, MMP-2 and MMP-9 expression were downregulated in siKLK12-transfected HT-29 cells. However, KLK12 overexpression elicited the opposite effect on those factors. Therefore, it was concluded that KLK12 may be involved in the process of EMT in colorectal cancer, at least in HT-29 cells.

Previous data supports the hypothesis that targeting apoptosis may be a promising and protective strategy for the management of colorectal cancer. MLK7-AS1 knockdown promoted CRC cell apoptosis in vitro (28). Lupeol-induced cellular apoptosis of both colorectal cancer cell lines, which increased p53 and decreased Bcl2 protein levels (29). In the present study, apoptosis levels and the expression levels of apoptosis-associated proteins were determined by flow cytometry and western blot analysis, respectively. It was identified that cell apoptosis was induced by the knockdown of KLK12 in HT-29 cells. In addition, the anti-apoptosis protein (Bcl-2) was expressed at low levels and the pro-apoptosis proteins (Bax and cleaved caspase-3) were expressed at high levels in the siKLK12 group, compared with the control group. However, KLK12 upregulation produced the opposite effect on those factors. These results suggested that the function of KLK12 as a carcinogenic factor in colorectal cancer may be realized by the inhibition of apoptosis, at least in HT-29 cells. However, the precise mechanisms underlying KLK12 activity in colorectal cancer required further investigation.

At present, the mechanism by which KLK12 induced viability and metastasis of colorectal cancer is not fully understood. AMPK, a ubiquitous serine/threonine protein kinase, regulates tumorigenesis, development and chemical resistance through negative regulation of mTOR (30). The phosphorylation of AMPK and inhibition of downstream phosphorylation of mTOR in cholangiocarcinoma cells were activated by FYN proto-oncogene, Src family tyrosine kinase knockdown (31). In the present study, the functions of KLK12 on AMPK/mTOR signaling were explored, and it was identified that the phosphorylation of AMPK was activated and downstream phosphorylation of mTOR was inhibited by KLK12 downregulation, while KLK12 overexpression inhibited the phosphorylation levels of AMPK and promoted phosphorylation of mTOR. Furthermore, the viability of KLK12 plasmid-transfected HT-29 cells incubated with AICAR or rapamycin was determined by MTT assay. It was identified that cell viability was improved by HT-29 cells, which was reversed by AICAR or rapamycin. These data demonstrated that the AMPK/mTOR signaling pathway was activated by KLK12 in colorectal cancer. siKLK12 inhibited the viability and EMT process of HT-29 cells via regulation of the AMPK/mTOR signaling pathway. However, the method by which KLK12 functions in colorectal cancer animal models or in patients with colorectal cancer remains unclear. The present study also demonstrated that rapamycin may produce limited effects on cell viability, compared with AICAR, and this may be explained by a more marked inhibition of AICAR on mTOR and its downstream genes.

Previous studies have indicated that KLK12 splice variant KLK12sv3 may be used as a marker in predicting a desirable prognosis in breast cancer (19). Papachristopoulou et al (32) described the value of KLK12sv1/2 and KLK12sv3 in differentiating between benign and malignant breast tumors and their potential prognostic value. We hypothesized that KLK12 expression may also be associated with the survival and prognosis of patients with colorectal cancer, however, whether it may be used as a prognostic marker for colorectal cancer remains to be explored. However, by referring to other studies $(33,34)$, the effects of KLK12 on cell proliferation and migration were verified. In the present study, it was identified that silencing KLK12 inhibited the cell viability and promoted apoptosis of human colorectal cancer HT-29 cells. However, colorectal cancer is a highly heterogeneous disease, and the role of KLK12 requires additional confirmation in multiple different colorectal cancer cells.

In conclusion, KLK12 down-regulation inhibited cell viability and metastasis via regulating AMPK/mTOR signaling pathway in HT-29 cells. The present results provided that KLK12 was an oncogene and could be used as a therapeutic target for treating colorectal cancer.

\section{Acknowledgements}

Not applicable.

\section{Funding}

This study was supported by the Zhejiang Provincial Traditional Chinese Medicine Science Research Foundation (grant no. 2016ZB037); the Natural Science Foundation of Zhejiang Province (grant no. LQ15H290004).

\section{Availability of data and materials}

The analyzed data sets generated during the study are available from the corresponding author on reasonable request.

\section{Authors' contributions}

QL and HZ made substantial contributions to the conception and design of the study. XZ and ZF were responsible for data acquisition, data analysis and interpretation. $\mathrm{HZ}, \mathrm{XZ}$ and $\mathrm{QL}$ were responsible for drafting the article and critically revising it for important intellectual content. All authors provided final approval of the version to be published. All authors are accountable for all aspects of the study in ensuring that questions related to the accuracy or integrity of the work are appropriately investigated and resolved. 


\section{Ethics approval and consent to participate}

All procedures performed in studies involving human participants were in accordance with the ethical standards of the institutional and/or national research committee and with the 1964 Helsinki declaration and its later amendments or comparable ethical standards. The present study was approved by the Ethical Committee of The First Affiliated Hospital of Zhejiang Chinese Medical University and written informed consent was obtained from each patient.

\section{Patient consent for publication}

Written informed consent was obtained from each patient.

\section{Competing interests}

The authors declare that they have no competing interests.

\section{References}

1. Torre LA, Bray F, Siegel RL, Ferlay J, Lortet-Tieulent J and Jemal A: Global cancer statistics, 2012. CA Cancer J Clin 65 : 87-108, 2015.

2. Brenner H, Kloor M and Pox CP: Colorectal cancer. Lancet 383 : 1490-1502, 2014

3. Das B, Sarkar N, Bishayee A and Sinha D: Dietary phytochemicals in the regulation of epithelial to mesenchymal transition and associated enzymes: A promising anticancer therapeutic approach. Semin Cancer Biol 56: 196-218, 2019.

4. Iwatsuki M, Mimori K, Yokobori T, Ishi H, Beppu T, Nakamori S, Baba $\mathrm{H}$ and Mori M: Epithelial-mesenchymal transition in cancer development and its clinical significance. Cancer Sci 101: 293-299, 2010

5. Nieto MA: The ins and outs of the epithelial to mesenchymal transition in health and disease. Annu Rev Cell Dev Biol 27: 347-376, 2011.

6. Thiery JP, Acloque H, Huang RY and Nieto MA: Epithelialmesenchymal transitions in development and disease. Cell 139: 871-890, 2009

7. Boesch M, Spizzo G and Seeber A: Concise review: Aggressive colorectal cancer: Role of epithelial cell adhesion molecule in cancer stem cells and epithelial-to-mesenchymal transition. Stem Cells Transl Med 7: 495-501, 2018.

8. Hardie DG and Sakamoto K: AMPK: A key sensor of fuel and energy status in skeletal muscle. Physiology (Bethesda) 21: 48-60, 2006.

9. Kim J, Kundu M, Viollet B and Guan KL: AMPK and mTOR regulate autophagy through direct phosphorylation of Ulk1. Nat Cell Biol 13: 132-141, 2011.

10. Lizcano JM, Göransson O, Toth R, Deak M, Morrice NA, Boudeau J, Hawley SA, Udd L, Mäkelä TP, Hardie DG and Alessi DR: LKB1 is a master kinase that activates 13 kinases of the AMPK subfamily, including MARK/PAR-1. EMBO J 23: 833-843, 2004.

11. Guertin DA and Sabatini DM: Defining the role of mTOR in cancer. Cancer Cell 12: 9-22, 2007.

12. Ji S, Tang S, Li K, Li Z, Liang W, Qiao X, Wang Q, Yu S and Ye M: Licoricidin inhibits the growth of SW480 human colorectal adenocarcinoma cells in vitro and in vivo by inducing cycle arrest, apoptosis and autophagy. Toxicol Appl Pharmacol 326: 25-33, 2017.

13. Thent ZC, Zaidun NH, Azmi MF, Senin MI, Haslan H and Salehuddin R: Is metformin a therapeutic paradigm for colorectal cancer: Insight into the molecular pathway? Curr Drug Targets 18: 734-750, 2017.

14. Clements J, Hooper J, Dong Y and Harvey T: The expanded human kallikrein (KLK) gene family: Genomic organisation, tissue-specific expression and potential functions. Biol Chem 382: 5-14, 2001

15. Di Meo A, Wang C, Cheng Y, Diamandis EP and Yousef GM: The miRNA-kallikrein interaction: A mosaic of epigenetic regulation in cancer. Biol Chem 399: 973-982, 2018.
16. Talieri M, Li L, Zheng Y, Alexopoulou DK, Soosaipillai A, Scorilas A, Xynopoulos D and Diamandis EP: The use of kallikrein-related peptidases as adjuvant prognostic markers in colorectal cancer. Br J Cancer 100: 1659-1665, 2009.

17. Lawrence MG, Lai J and Clements JA: Kallikreins on steroids: Structure, function, and hormonal regulation of prostate-specific antigen and the extended kallikrein locus. Endocr Rev 31: 407-446, 2010.

18. Liu Y, Lu Z, Cui M, Yang Q, Tang Y and Dong Q: Tissue kallikrein protects SH-SY5Y neuronal cells against oxygen and glucose deprivation-induced injury through bradykinin B2 receptor-dependent regulation of autophagy induction. J Neurochem 139: 208-220, 2016.

19. Talieri M, Devetzi M, Scorilas A, Pappa E, Tsapralis N, Missitzis I and Ardavanis A: Human kallikrein-related peptidase 12 (KLK12) splice variants expression in breast cancer and their clinical impact. Tumour Biol 33: 1075-1084, 2012.

20. Kwon Y, Park M, Jang M, Yun S, Kim WK, Kim S, Paik S, Lee HJ, Hong S, Kim TI, et al: Prognosis of stage III colorectal carcinomas with FOLFOX adjuvant chemotherapy can be predicted by molecular subtype. Oncotarget 8: 39367-39381, 2017.

21. Livak KJ and Schmittgen TD: Analysis of relative gene expression data using real-time quantitative PCR and the 2(-Delta Delta C(T)) method. Methods 25: 402-408, 2001.

22. Geng X, Liu Y, Dreyer T, Bronger H, Drecoll E, Magdolen V and Dorn J: Elevated tumor tissue protein expression levels of kallikrein-related peptidases KLK10 and KLK11 are associated with a better prognosis in advanced high-grade serous ovarian cancer patients. Am J Cancer Res 8: 1856-1864, 2018.

23. Tailor PD, Kodeboyina SK, Bai S, Patel N, Sharma S, Ratnani A, Copland JA, She JX and Sharma A: Diagnostic and prognostic biomarker potential of kallikrein family genes in different cancer types. Oncotarget 9: 17876-17888, 2018.

24. Li XS and He XL: Kallikrein 12 downregulation reduces AGS gastric cancer cell proliferation and migration. Genet Mol Res 15: 2016.

25. Lose F, Batra J, O'Mara T, Fahey P, Marquart L, Eeles RA, Easton DF, Al Olama AA, Kote-Jarai Z, Guy M, et al: Common variation in Kallikrein genes KLK5, KLK6, KLK12, and KLK13 and risk of prostate cancer and tumor aggressiveness. Urol Oncol 31: 635-643, 2013.

26. Zhao EH, Shen ZY, Liu H, Jin X and Cao H: Clinical significance of human kallikrein 12 gene expression in gastric cancer. World J Gastroenterol 18: 6597-6604, 2012.

27. Kryza T, Parent C, Pardessus J, Petit A, Burlaud-Gaillard J, Reverdiau P, Iochmann S, Labas V, Courty Y and Heuzé-Vourc'h N: Human kallikrein-related peptidase 12 stimulates endothelial cell migration by remodeling the fibronectin matrix. Sci Rep 8: 6331, 2018.

28. Zhang R, Li J, Yan X, Jin K, Li W, Liu X, Zhao J, Shang W and Zhao X: Long noncoding RNA MLK7AS1 promotes proliferation in human colorectal cancer via downregulation of p21 expression. Mol Med Rep 19: 1210-1221, 2019.

29. Wang Y, Hong D, Qian Y, Tu X, Wang K, Yang X, Shao S, Kong $X$, Lou $Z$ and Jin L: Lupeol inhibits growth and migration in two human colorectal cancer cell lines by suppression of Wnt- $\beta$-catenin pathway. Onco Targets Ther 11: 7987-7999, 2018.

30. Cork GK, Thompson J and Slawson C: Real Talk: The inter-play between the mTOR, AMPK, and hexosamine biosynthetic pathways in cell signaling. Front Endocrinol (Lausanne) 9: 522, 2018.

31. Lyu SC, Han DD, Li XL, Ma J, Wu Q, Dong HM, Bai C and He Q: Fyn knockdown inhibits migration and invasion in cholangiocarcinoma through the activated AMPK/mTOR signaling pathway. Oncol Lett 15: 2085-2090, 2018.

32. Papachristopoulou G, Tsapralis N, Michaelidou K, ArdavanisLoukeris G, Griniatsos I, Scorilas A and Talieri M: Human kallikrein-related peptidase 12 (KLK12) splice variants discriminate benign from cancerous breast tumors. Clin Biochem 58: $78-85,2018$.

33. Jia S, Qu T, Wang X, Feng M, Yang Y, Feng X, Ma R, Li W, Hu Y, Feng Y, et al: KIAA1199 promotes migration and invasion by Wnt/ $\beta$-catenin pathway and MMPs mediated EMT progression and serves as a poor prognosis marker in gastric cancer. PLoS One 12: e0175058, 2017.

34. Yang D, Du G, Xu A, Xi X and Li D: Expression of miR-149-3p inhibits proliferation, migration, and invasion of bladder cancer by targeting S100A4. Am J Cancer Res 7: 2209-2219, 2017.

This work is licensed under a Creative Commons Attribution-NonCommercial-NoDerivatives 4.0 International (CC BY-NC-ND 4.0) License. 